\title{
Experiences of registered and student nurses regarding the clinical supervision in medical and surgical wards: Develop an educational programme to support registered nurses
}

\author{
Hanna Neshuku*, Amukugo Hans Justus \\ lecturers, School of nursing, Faculty of health Sciences University of Namibia \\ *Corresponding author E-mail: hneshuku@unam.na
}

\begin{abstract}
The purpose of the study was to explore and describe the lived experiences of registered nurses and student nurses regarding the clinical supervision of student nurses in medical and surgical wards. The findings will be a basis to develop an educational programme to support registered nurses during clinical supervision in the same context.

The study was a qualitative, explorative, descriptive and contextual in nature. This paper describes Phase 1, of the study aimed to explore and describe the experiences of registered nurses and student nurses regarding clinical supervision of student nurses. Data was collected through in-depth individual face to face interviews thereafter data were analysed based on the Tesch's method of qualitative data analysis The numbers of interviews conducted were 35 in total, made up of 27 interviews with student nurses and 8 interviews with registered nurses. The numbers were determined based on the subject who availed themselves for the study as well as data saturation.

Study revealed managerial, educational as well as non-conducive environment challenges experiences by registered nurses and student nurses during clinical supervision of student nurses.

It was concluded that educational programme should be developed in order to support registered to manage those challenges. The development of the programme is outlined in article part 2.
\end{abstract}

Keywords: Experiences; Clinical Supervision; Support; Registered Nurses and Student Nurses.

\section{Introduction}

The concept clinical supervision is defined differently by several authors. Some are focusing on the aspect of "how" clinical supervision is done while others focus on the "what" of clinical supervision. Bezuidenhout (2003) refers to clinical supervision as a professional entering into a relationship with the practical situation and having confidence to enter into an equal partnership with other health care professionals in their quest to make a real contribution to health and health care. Another definition by Consedine (2004) views clinical supervision as a term used to describe a formal process of professional support and learning, which enables students to develop knowledge and competences and assume responsibility for their own practice. Clinical supervision is the term used to describe an educational relationship between an experienced nurse and nursing students (Dictionary of Nursing, 2008). It also regarded as a process of professional support and learning in which nurses develop their practices Brunero \&Stein Parbury (2010). The purpose of clinical supervision is to improve nursing practices (Van Ooijen 2000). In the context of the students nurse if students are to acquire knowledge and skills in clinical practices, then the registered nurses must be there to supervisor and demonstrate how theoretical knowledge can be intergraded into practice (Löfmark, Thorkildsen, Råholm\& Natvig 2012). The registered nurse should be the mirror of professional conduct to students. Dale, Leland and Dale (2013) view clinical supervision as an important aspect that can be used to facilitate ethical devel- opment so that students can be encouraged to reflect on their experiences related to handling ethical issues in clinical settings.

The aim of learning in clinical practice is to enable student nurses to develop in the domains of competence and to become safe, caring and competent decision-makers (Preceptorship, 2003).

Clinical supervision is seen as important tools because it enables the students understand patient care, improve patient care, maintaining standard of care (Brunero \&Stein and Parbury 2010). Sharif and Masouri (2005) hold the opinion that it prepares student nurses to be able to master the art of "doing" as well as "knowing" the clinical principles in practice. It further stimulates students to use their critical thinking skills for problem solving. Both education and service institutions share in the creation of a supportive learning milieu. To master the discipline of nursing and the increasingly complex skills required to deliver safe and effective patient care, both theoretical and clinical practice are essential for nursing students (American Association of Colleges of Nursing, 2011).

This paper is part of the study done to develop, implement and evaluate an educational programme to support registered nurses in clinical supervision of student nurses in medical and surgical wards of training health facilities in the Oshana region in Namibia. The researcher concentrated on clinical supervision in the medical and surgical wards of training hospitals in Oshana region, Namibia only.

Student nurses acquire the knowledge, skills and values necessary for professional practice through clinical supervision. It is only in a safe and secure environment that students can develop self- 
awareness and self-confidence. The environment in which students and the registered nurse meet for an educational encounter should be conducive to learning. However, a conducive and supportive learning environment depends on the availability of support systems. Such support systems include supervision, a conducive and supportive learning environment, and a good relationship between the faculties, registered nurses in the clinical area and student nurses (Begat \& Serevinsson, 2003). As a result, a situation analysis was carried out to identify the need for the development of an educational programme to support registered nurses to enable them to provide effective clinical supervision to student nurses. This helped the researcher to gather information from registered nurses and student nurses and thus to accommodate views and needs of both groups during the development of the programme (Kirby, 2000; Holliday, 2005).

\section{Purpose}

For the context of this paper the purpose is to discuss the research design and methods used during Phase 1 (situational analysis) of the study to describe and explore the lived experiences of registered nurses and nursing students about clinical supervision of nursing students in medical and surgical wards in training heath facilities of the Oshana Region in Namibia as well as results thereof.

\section{Methodology}

The research design for the study was qualitative, descriptive, exploratory, and contextual in nature explored and described lived experiences of registered nurses in relation to supervision of nursing students within the context of clinical settings in the medical and surgical wards at a training health facility in the Oshana Region.

\subsection{Data collection}

This study was conducted at the Oshakati Intermediate hospital, one of the nursing training hospitals in Oshana region, where student nurses are allocated for clinical practice for medical and surgical nursing. Some of the registered nurses were drawn from the University of Namibia Oshakati campus because they also serve as supervisors of those student nurses while at practice in Oshakati Intermediate hospital. The population for this phase were all the students who are enrolled for the Comprehensive Diploma in Nursing and Midwifery Science and Bachelor degree in Nursing Science at the University of Namibia on full time basis and who were allocated to the medical and surgical wards of the training hospital Oshakati Intermediate hospital or UNAM Oshakati Campus training institution in the Oshana region, Namibia as well as registered nurses who are supervising the clinical learning of students following the above-mentioned programme in the medicalsurgical wards of the Oshakati Intermediate training hospital in Oshana region.

The participants were consisted of 27 student nurses and eight registered nurses. ). A purposive sampling was used to select the participants because according to Welman, Kruger and Mitchell (2009) and Shank (2006), it is essential for the researcher to discover who will be the most legible participants and those with an abundance of pertinent information. With purposive sampling, the sample is selected because it contains characteristics that are the same as that of the population. Purposive sampling technique entails a process of selection so that the maximum information required for qualitative research will be provided (Qualitative methodology, 2008). The inclusion criteria for the study were that student nurses have to be registered for the Comprehensive Diploma in Nursing and Midwifery Science and Bachelor's Degree in Nursing Science on a full time basis at the University of Namibia, Oshakati Campus and are allocated to the medical and surgical wards in the Oshakati intermediate hospital (a training hospital) in the Oshana region. These student nurses should be in their second or third year of their academic year, whether irrespective whether they are doing it for the first time. Furthermore, registered nurses have to be employed in Oshana health facility (Oshakati intermediate hospital) for at least a year. Registered nurses should be those who are involved in the supervision of those student nurses during clinical practice in the medical and surgical wards Vos, Strydom, Fouche \& Delport 2007; Brink et al., 2008)

Data was collected by means of individual face to face interviews as follows. Prior to the commencement of the interview, the researcher welcomed the participant in the interview room, offered him/her a chair and informed him/her to feel comfortable and welcomed. Furthermore, the researcher read the letter requesting consent to the participants, who subsequently gave their verbal informed consent and the researcher re-emphasized the purpose and objectives of the study. The participants were informed to be open answer the questions the way they feel is correct to do so and to also ask questions if there is something they did not understand. Participants were further informed about the use of the audiotape, and they could say whether an audiotape can be used or not. However, the use of audio recording was important because information obtained from interviews if recorded will provide a good record with referential adequacy, an aspect which ensures credibility (Babbie \& Mouton, 2007). Therefore, a tape recorder was used to record everything that was said for analysis (De Vos, 2007); however, interviewees had the opportunity to indicate to the researcher if they preferred that a tape recording should not be used. Individual in-depth interviews were conducted for the participants to describe their experiences regarding clinical supervision of student nurses in medical and surgical wards. The numbers of interviews conducted were 35 in total, made up of 27 interviews with student nurses and eight interviews with registered nurses. The numbers were determined based on the subject who availed themselves for the study as well as data saturation. The sample size was determined by data saturation. In this study, the data was saturated, this was observed when the participants started to respond, and their responses were a repetition of already mentioned issues or concepts, without adding new information. Criterion sampling method was applied; therefore, only participants with certain criteria were selected (Holliday, 2003, Boeije, 2009). Criteria for selection focussed on various subjective and rationally selected characteristics of the whole population from which the sample will be drawn.

\subsection{Data analysis}

Data analysis in this study refers to qualitative data analysis as a search for general statements about relationships among categories of data. This involves descriptive examination of the participants' narrative, discussion of field note taking, details of data arrangement and storage, and where appropriate the categories and clusters that were used to make sense of the data ( Gorman \& Clayton, 2005; Williamson, 2005).

Data analysis was done by applying Tesch's method of open coding (Saks \& Allsop, 2007; Kobus, 2007). This is a process of breaking down, examining, comparing and categorizing the raw data and at the end putting them together in a new way (De Vos et al., 2007). This method was chosen because it is a systematic approach, and its procedures have been clearly described. The stages of data analysis were done based on the Tesch method of qualitative data analysis as proposed by Creswell (2008)

Step 1: Data transcription: Interviews were audio taped and subsequently transcribed verbatim. Olivier, Serovick and Mason (2005) view this transcription of data as being pivotal to qualitative inquiry. The following steps were employed namely:

- The researcher read through all of the transcripts from the interview data noted from observation and gathered as field notes, listened to the taped information on the cassette, carefully transcribed all taped interviews word for word, jotting down some ideas as they came to mind. It helped her to famil- 
iarize herself with the data and get a global understanding of the whole.

- List of all topics was made and similar topics were clustered together to form themes.

- The researcher organized subthemes to see the development of themes

- The most descriptive wording for the topics was found and turned into subthemes. Subthemes were reduced by grouping topics together that related to each other

- Related subthemes were identified, grouped together and themes for each group were identified.

Step 2: Data's reduction: After the data was transcribed, the interview transcripts were read through several times to obtain a sense and meaning of the whole. To ensure trustworthiness of the transcribed data, the researcher kept transcripts and the audio taped interview information for referral. Transcriptions were sent to the study supervisor as per request to check whether all information was included in the study; this was done to prevent any information to be left out. Topics were identified and noted down in the transcriptions' document. Thereafter, topics were recorded in columns.

Topics with the same meaning were linked together with lines This resulted in the identification of sub-themes. These subthemes should be relevant for the research purpose. Throughout the analysis, the researcher attempted to gain a deeper understanding of registered nurses and student nurses' experiences. The findings were supported by verbatim quotes from the interviews, and they were sustained by relevant literature. A review of literature is conducted to generate a picture of what is known and not known about a particular situation. That information forms the background of the study (Walliman, 2005; Babbie et al., 2007, Streubert Speziale and Carpenter (2007). Topics with the same meaning were linked together then three (3) and eleven (11) sub-themes were identified as illustrated in table1.

\section{Results and discussion}

The purpose under the literature control is to relate the findings within the context of the existing body of knowledge and current trends on the phenomenon under study in order to observe a confirmation or a contradiction of existing literature. On the other hand, the literature control allows the researcher to state new insights from the current study that serves as a contribution to the existing literature De Vos et al., 2007). The literature control for this study was done after the data analysis as suggested by Streubert, Speziale and Carpenter (2007), who argue that in a phenomenological study, a literature review should be carried out following the data analysis in order to avoid bias based on preconceived knowledge about the phenomenon.

Three themes and 11 sub-themes were identified. The discussions of the themes and sub-themes about the participants' experiences were done in relation to the existing body of knowledge suggested by Forrester (2008). The themes and subthemes are illustrated as table 1 .

Table 1: Themes and sub-themes

\begin{tabular}{|c|c|}
\hline Themes & Sub-themes \\
\hline \multirow{6}{*}{$\begin{array}{l}\text { 1. Registered nurses and student } \\
\text { nurses experiences managerial challenges } \\
\text { during clinical supervision of student } \\
\text { nurses by registered nurses }\end{array}$} & Too much work \\
\hline & load and shortage of staff \\
\hline & Lopsided supervi- \\
\hline & sor/ student ratio \\
\hline & 1.3 Absence of clini- \\
\hline & cal instructors in some wards \\
\hline \multirow{6}{*}{$\begin{array}{l}\text { 2. Educational challenges were another } \\
\text { experiences of registered nurses and } \\
\text { student nurses during clinical supervision } \\
\text { of student nurses by registered nurses }\end{array}$} & $\begin{array}{l}\text { 2.1 Lack of knowledge of } \\
\text { supervision role }\end{array}$ \\
\hline & 2.2 Gap between theory and \\
\hline & practice \\
\hline & $\begin{array}{l}2.3 \text { Supervisors were outdat- } \\
\text { ed and }\end{array}$ \\
\hline & 2.4Supervisors are providing \\
\hline & $\begin{array}{l}\text { ineffective clinical supervi- } \\
\text { sion to student nurses }\end{array}$ \\
\hline
\end{tabular}

3 Registered nurses and student nurses experience non-conducive environment during clinical supervision
3.1 Poor guidance of student nurses by registered nurses 3.2 Poor interpersonal relationship between supervisors and students

3.3 Poor communication among supervisors and students

3.4 Hospital stock shortage

\subsection{Theme 1: managerial challenges}

Respondents expressed clear views on how the workload and the shortage of staff prevent effective clinical supervision. Shortage of staff results in an increased workload and registered nurses had little time to supervise students. Registered nurses communicated the following regarding the shortage of staff and the heavy workload:

"We are trying to supervise students but patient care prevents us to concentrate on students as the burden is too big; patients are too many and wards are understaffed. Sometimes we are not coping due to overcrowded wards; we prefer to give time to our patients." "In this ward we have been very few registered nurses. We don't always have time to guide and teach students properly; those are allocated to our ward."

Student nurses draw on their experiences in clinical supervision regarding workload as follows:

"Sometimes supervisors have no time to teach students, students try to learn through experience as per delegation without guidance and it is not always easy."

"I experience a lot of problems with supervision in the ward as registered nurses are too busy with patient care"

"Yes registered nurses in wards are most of the time overloaded with work therefore they do not have time to assist students in doing procedures. It is an overwhelming experience that I have gained when working in the wards."

The quotations above are a clear indication that the respondents in this study experienced challenges with supervision, caused by the shortage of staff and too heavy a workload. Wards were found to be overcrowded due to a big number of patients and students. This has been a problem which prevented registered nurses to provide proper supervision to students. Kemper (2007) concurs that the presence of students in the ward was seen as an added burden by ward nurses.

A study done by Magobe, Beukes and Muller (2010) found that the shortage of staff is one of the factors identified as obstacles to the facilitation of student nurses' learning in clinical areas. Moeti, Van Niekerk and Van Velden (2004) concur with the findings of this study by, stating that due to a shortage of staff, it was difficult for the professional nurses to guide and supervise the newly registered ones sufficiently. Similar results were found by Magobe, Beukes and Muller's (2010) study where participants perceived the shortage of staff as contributing to students' poor clinical competence due to a lack of mentoring. This was in turn caused by the shortage staff or mentors who were overloaded with ward work, and they were not able to supervise student nurses. In the same study it was also found that students, due to the shortage of nursing staff and too many workloads, were regarded as part of the staff or workforce and not as students who need to practice their practical skills as such. Findings of a study done by Castledine (2002) support the above findings by indicating that an increased workload and limited time were two major reasons for nurses being reluctant to supervise student nurses.

The findings correlate with those of a study that was done by Mochaki $(2001$, p. 86) which found that both ward sisters and college tutors were unable to teach and supervise students effectively in clinical practice because of a shortage of staff and an increased workload. As a result, because of a shortage of staff, registered nurses in wards had no other option but to direct their energies to the needs of patients rather than to students. Another finding of a study by Castledine (2002) supports the above mentioned findings by stating that an increased workload and limited time are two 
major reasons causing reluctance in registered nurses when it comes to the clinical supervision of student nurses, (Bestern, 1992 as cited in Van Rhyn et al., 2004).

Waldock (2010) states that time, and workloads are considered as key factors contributing to the reduced learning opportunities of student nurses. The workload needs to be reduced for nurses supervising students because time and workload are significant barriers that impact negatively on clinical supervision. The phenomenon stated under the previous statement is supported by a study done by Clarle, Gibb and Rampageous (2003) as one of the major reason nurses are unwilling to supervise student nurses. Another study which identified the workload as a critical factor is a study done by Abid, Hagbaghry, Sabbali and Ahmadi (2004). They further stated that the workload needs to be reduced for nurses to be able to supervise students during clinical practice. In a study by Spouse (2000) it was revealed that busy wards and inadequate staff levels contributed to inadequate and irregular supervisions of student nurses. Moeti et al., (2004) share similar views that the shortage of staff has a negative influence on student nurses' learning during clinical practice.

However, the researcher is of the opinion that registered nurses should fulfil an important function as socializing agents for providing supervision to student nurses.Management is a process of influencing others with the specific intention of getting them to perform effectively and contribute to meeting the desired goal.In this study it was found that many registered nurses do not provide effective clinical supervision to the student nurses due to managerial challenges. The following sub-themes as indicated in table 1 were identified under managerial challenges that registered nurses encountered during clinical supervision of student nurses.

Too much work load and shortage of staff

Respondents expressed clear views on how the workload and the shortage of staff prevent effective clinical supervision. Shortage of staff results in an increased workload and registered nurses had little time to supervise students.

Registered nurses communicated the following regarding the shortage of staff and the heavy workload:

"We are trying to supervise students but patient care prevents us to concentrate on students as the burden is too big; patients are too many and wards are understaffed. Sometimes we are not coping due to overcrowded wards; we prefer to give time to our patients." "In this ward we have very few registered nurses. We don't always have time to guide and teach students properly, those are allocated to our ward."

Student nurses draw on their experiences in clinical supervision regarding workload as follows:

"Sometimes supervisors have no time to teach students, they say that they are too few and have other responsibilities, students try to learn through experience as per delegation without guidance and it is not always easy."

"I experience a lot of problems with supervision in the ward as registered nurses are too busy with patient care"

"Yes registered nurses in wards are most of the time overloaded with work. Therefore, they do not have time to assist students in doing procedures. It is an overwhelming experience that I have gained when working in the wards."

The quotations above are a clear indication that the participants for this study experienced challenges with supervision, caused by the shortage of staff and too heavy a workload. Wards are overcrowded due to a big number of patients and students. This has been a problem which prevented registered nurses to provide proper supervision to students. Kemper (2007) concurs with the previous findings because findings from her study also reported that the presence of students in the ward was seen as an added burden by ward nurses. A study done by Magobe, Beukes and Muller (2010) found that the shortage of staff is one of the factors identified as obstacles to the facilitation of student nurses' learning in clinica areas. Moeti, Van Niekerk and Van Velden (2004) concur with these findings, stating that due to a shortage of staff, it was difficult for the professional nurses to guide and supervise the newly registered ones sufficiently. Similar results were found by Mago- be, Beukes and Muller's (2010) study where participants perceived the shortage of staff as contributing to students' poor clinical competence due to a lack of mentoring. This was in turn caused by the shortage staff or mentors were overloaded with ward work, and they were not able to supervise students as they are overloaded. In the same study, it was also found that students, due to the shortage of staff and too many workloads, they were regarded as part of the staff or workforce and not as students who need to practice their practical skills as such. The findings correlate with those of a study that was done by Mochaki (2001) which found that both ward sisters and college tutors were unable to teach and supervise students effectively in clinical practice because of a shortage of staff and an increased workload. As a result, registered nurses in wards had no other option but to direct their energies to the needs of patients rather than to students.

Waldock (2010) states that time and workloads are considered as key factors contributing to the reduced learning opportunities of students. The workload needs to be reduced for nurses supervising students because time and workload are significant barriers that impact negatively on clinical supervision. The phenomenon stated under the previous statement is proven by a study done by Clarle, Gibb and Ramprogous (2003) as one of the major reason nurses are unwilling to supervise student nurses. Another study which identified the workload as a critical factor needs to be reduced for nurses to be able to supervise students during clinical practice.is a study done by Abid, Hagbaghry, Sabbali and Ahmadi (2004). In a study by Spouse (2001) it was revealed that busy wards and inadequate staff levels contributed to inadequate and irregular supervisions of student nurses. Moeti et al., (2004) share similar views that the shortage of staff is has a negative influence on student nurses' learning during clinical practice.However, the researcher is of the opinion that registered nurses should fulfil an important function as socializing agents for providing supervision to students.

Lopsided supervisor/ student ratio

During the interview, it was reported that there is a too-large supervisor/student ratio. This may have negative effects on student learning, because it prohibits some positive health practices and reduces the assistance given to students. The researcher found it evident in the results that a too-large supervisor/student ratio is promoting an inadequacy of student supervision. These were highlighted by the following statements by nursing students:

"Supervisors are trying to teach us but most of the time they are overloaded with ward work and sometimes we don't get time for all of us to practice because we are too many"

"So far the clinical environment is not good because although registered nurses are trying to supervise students they cannot cope, sometimes during supervision some students are left unattended while supervisors are attending to some because the number allocated to them is not manageable"

"Some registered nurses used to supervise us in groups but those who are not in a group during that time is left unattended, and they end up not learning anything because we are too many and supervisors are too few."

Registered nurses responded to the challenge about the too large supervisor/student ratio by stating the following:

"We cannot supervise student nurses properly because we are also doing ward activities, tasks are too many and we really can't cope"

"In our ward there are only two registered nurses and the ward is most of the time busy therefore there is no time for guiding students"

"Nowadays wards are overloaded with student nurses, although the number of registered nurses has not been looked at students are too many to be supervised by the available registered nurses in the wards"

The clinical environment should provide teaching and learning opportunities, as well as adequate human resources to provide supervision. It can be deduced that when student nurses are allocated to the same clinical area in large numbers, it affects teaching and learning negatively as registered nurses won't be able to give 
them the necessary support resulted in students not being competent to some tasks when completing their study. Therefore, the number of student nurses allocated to any unit at a time should be controlled if effective supervision is to be achieved. In a study done by Magobe et.al (2010) on the reasons for student nurse's poor clinical competences in primary health care and clinical nursing diagnoses and treatment, it was reported that the shortage of personnel creates a crisis health care situation and contributes to the students' poor clinical competence.

The findings of a study done by Hlongwa (2003) supported this observation by stating that the increased number of student nurses in clinical practice brings an additional strain and workload to the already short-staffed and overworked registered nurses. This means that opportunities for learning such as role modelling, clinical supervision, ward rounds, teachable moments and others are compromised when the registered nurses focus their energy on patient care only. Basteenbier (1992, as cited in Van Rhyn and Gontsana, 2004) in the study of stress experienced by nursing students during clinical practice also found that too many student nurses were allocated to the wards at the same time.

Similar findings were revealed during the interview of Klerk (2010) who said that while in the hospital, student nurses were not properly supervised and trained due to the large number of student nurses allocated to one setting.

According to Landmark, Hansen, BjonesBohler (2003), it was found that registered nurses were experiencing difficulties in controlling large numbers of student nurses in one clinical area. This is a view which was also supported by Klerk (2010) who revealed that due to a large number of student nurses, registered nurses start to develop negative attitudes towards clinical supervision and which in turn affects the learning process of student nurses.

Mhlongo (1996, as cited in Mabuda, 2008) found that too many student nurses in clinical settings have a negative influence on the clinical supervision of student nurses. Participants of the same study by Mabuda (2008) also revealed that a large number of students in clinical settings hamper their clinical learning. In a study by Van Ryn et al (2004) participants reported that they were allocated in large numbers to one unit, which resulted in that they were unable to learn because of the poor supervision and insufficient learning opportunities. According to the findings of this study, the researcher concurs with the previous study findings and concludes by stating that the big supervisor/student ratio is one of the challenges in clinical supervision.

Absence of clinical instructors in some wards

The absence of clinical supervisors in some wards was another challenge learned from the interviews as a contribution with a negative effect on the clinical supervision of student nurses.

The following quotations from student nurses are evidence of this: "We have to go back to our old style, that style when there were clinical instructors who were responsible for practical teaching of students; the clinical instructors are up to date with what students need to learn in wards rather than some other supervisors because they are undergoing refresher training rather than any other supervisors therefore we need them to be present in each ward".

"I only see clinical instructors when they come to do clinical assessments, I don't see them on a daily basis, sometimes they are not supervising student nurses, they say that they are only for enrolled nurses".

Registered nurses on the other side expressed the following regarding the absence of clinical supervisors in some wards:

"Some supervisors did not undergo the same training like the one offered today, and this makes it too difficult for them to help students allocated to their wards and there is nobody to help them on how to supervise those students allocated in their wards."

"Clinical instructors in this hospital are allocated as if in-charge of the wards just like other registered nurses. They are responsible for taking care of patients in the ward where they are allocated; they do not get time to supervise student nurses."

According to the findings of a study done by Ohaya (2010, p. 5) participants in that study indicated that the clinical instructors' presence in the clinical area was not felt that much, even where it was needed. Brown, Herd, Humphries and Parton (2004) support the pervious statement by stating that students appreciate the presence of teachers in the wards. In the study done by Mabuda et al (2008), participants indicated that there are no clinical preceptors/instructors. Therefore, in their absence practical learning was too difficult. However, student nurses felt that clinical teachers need to be more available in clinical situations. The previous statements are supported by Lambert and Glecken (2005) who state that clinical nurse educators' role is to enhance learning through the provision of opportunities for learning. In a study by Burns and Paterson (2004) on clinical supervision and placement support, it was found that mentors (clinical instructors) are key components for effective clinical practice. These findings are similar to those of the study by Andrew, Bodie, Andrews, Wong, Rixon and Tomas (2006) which revealed that student nurses experienced no mentor assigned to them for the whole duration of their placement. Furthermore, the findings above are supported by a study done by Sharif and Masoumi (2005) which found that college tutors were not doing the accompaniment of student nurses. Based on the above research findings, it seems that clinical practice guidance by lecturers does not always function optimally. However, in a study by Burns and Paterson (2004) on clinical supervision and placement support, it was found that mentors (clinical instructors) are key components for effective clinical practice.

In the study done by Sharif and Masoumi(2005), the majority of participants had the perception that instructors were having more evaluative roles than the teaching role and they were not available every time.

\subsection{Educational challenges}

The findings of this study revealed the following educational challenges and these were expressed by both participants (registered nurses and student nurses): poor guidance of student nurses by registered nurses as well as lack of knowledge about the supervision role. Furthermore, the study revealed that the need in the education and training of registered nurses on supervision-related issues was a concern for most of the participants. They were of the opinion that registered nurses need to be educated about their roles and responsibilities during clinical supervision. Participants felt that supervision training needed to be given. This can be done by educating or updating registered nurses on how to provide clinical supervision and providing them with relevant information on issues related to supervision. The following sub themes emerged from the data collected.

\section{- Lack of knowledge of supervision role}

Transition from classroom into the reality is the point at which many of the previous problems in clinical supervision arose. Registered nurses expressed their lived experiences as follows:

"Practice programmes for student nurses are not always clear for us in the wards. What is not clear is what students on different levels should know and learn at practical settings"

"I was just selected to be a supervisor but furthermore nothing was done to prepare me for that, which I feel it was needed because I need guidance on how to supervise student nurses effectively".

Student nurses expressed the following:

"Some registered nurses don't want students to practice some procedures, for example, drawing of blood samples; they just want them to do full wash every day."

"Registered nurses do not allocate students according to their year of study where they can get opportunities to learn and finish their practical work books; instead they send us to do full wash observations and baby weighing which was the first year's work".

"I observed that the supervision in wards depends on the registered nurse the student nurses are working with. There are registered nurses who offer guidance and support to students while some registered nurses just tell students to go and perform a certain procedure so that she will come and see later. Students are learning, if registered nurses come only to check later sometimes the student did not do the procedure the proper way; the student 
will do mistakes or even not do the procedure at all because she doesn't know."

Findings of a study done by Ip and Chan (2005) revealed the same situation by stating that the lack of knowledge of tutors and ward sisters on how to implement or integrate primary healthcare approaches in the subjects that were taught in clinical sessions, was leading to ineffective guidance of student nurses. A similar picture was found through a study done by Sharif and Masoumi (2005) where one student participant stated that some nursing staff have good interactions with nursing students, and they are interested in helping student nurses in clinical placement, but they were not aware of the skills and strategies which were necessary in clinical education, and they are not prepared for their role to act as instructors in clinical placement. Appropriate preparation for the supervising role has been identified as one of the keys to reducing frustration and role confusion for registered nurses working with students. It also enhances student performance and enables the registered nurses to review their own level of knowledge. A study done by Magobe et.al. (2010) revealed that some preceptors/ supervisors were not prepared for the supervision role. According to study done by Van Rhyn and Gontsana (2004), based on the responses from the participants indicated that registered nurses were found unable to impart knowledge to students, and they showed minimal interest in the student learning process. Carlson et al., (2003) in their study identified a lack of awareness about the need of student nurses in clinical environment as an important factor leading to poor supervision.Adiss and Karadag (2003) in their study found that students were supervised by nursing staff that were not adequately trained in student supervision. In addition to addition to the above mentioned, a study by Tanner (2001) found that registered nurses lack clear guidelines and insight on what their role entails during the clinical supervision of student nurses. Sardos et al., (n.d) indicates that a lack of knowledge on the clinical supervision role is another factor resulting in the supervisor failing to provide effective clinical supervision. It was clear for the researcher that some of those problems can be avoided by adequate planning and preparation of both student nurses and clinical staff on clinical supervision and some of them can be improved by improving knowledge and practice on supervision roles.

- Gap between theory and practice

Most researches done on clinical supervision reveal a gap between theory and practice (Kelly 2007; Longley, Shaw \& Dolan 2007). The same picture was found by this study.

In a study by Sharif and Masoumi (2005), it was reported that students experienced confusion in the wards because of discrepancies between what is taught in class and what is actually implemented in the clinical environment. Kaphagwani and Uscb (2013) state that theory forms the basis for learning what students have to apply in the clinical practice in order to make meaning from theory. A study done by Safadi, Saleh, Amre\&Froclicher (2011) discovered that students also reported disparities between what was learned outside the classroom and simulation laboratory and the actual practice in clinical practice; these findings are similar to what was revealed by the participants of this study. They indicated that they experience a problem of correlation between theory and practice with specific reference to practical procedures. The following statements are accounts of this phenomenon:

"Things that are learned in class are not done the same in practice. Like the way procedures are taught in class is not done the same way, at practice people have their own style of doing things; this makes me to be confused because I don't know who is correct and who is wrong and not knowing which way to follow."

"Nurses in the clinic laughed at me saying how can you do all of these things according to the principles. There is no time to do it." One registered nurse participant said:

"The way you were taught to do things in class is not the same way we do things in practice and we have been doing it for a long time and no client died because of that, so we are not in wards for signing practical books for students, we are here for our patients." A study done by Sharif and Masoumi (2005) revealed that student nurses felt confused in the clinical settings when they realised how different it is between the ideal nursing taught and that of clinical settings. They perceive that there are differences between theory and practice. For example, the students found that the theory they had learnt about medication administration and aseptic techniques were not practiced in the clinical settings by nurses and other clinical staff. When they tried to apply theory in practice, they found that they were unable to do so. They were also given little support. In Van Rhyn and Gontsana's study (2004), participants revealed that lack of integration of theory in practice resulted ineffective teaching and learning as well as de-motivation of student nurses. In a study by Ohaya (2010), student participants expressed their learning in classroom as different from the reality they found in clinical settings by finding some practices as not "evident based". According to Mabuda et al., (2008), participants in their study indicated that there were discrepancies between theory taught in class and what is actually happening in clinical settings and this confused student nurses. Reports of the same study indicate also that college tutors are not accompanying students at practice to enforce what they taught them in class into practice and this left students with no option other than to agree to what registered nurses are telling them.

From the above studies, it becomes clear that there is a serious challenge in terms of the integration of theory into practice and this problem seems to persist despite numerous research studies and recommendations on this issue.

- Out-dated supervisors:

One student participant emphasized the need for education when he stated the following:

"Courses have been changed such that there might be some things that have been changed too and not all registered nurses are aware of it. They need to be updated, and the lecturers are not informing them about those changes and what their students need."

According to Searle, Human and Mogtline, (2009), the assessment of knowledge and skills should be carried out by competent nurses in order to ensure safe patient care. However, results of this study identified knowledge and skills of supervisors out-dated in providing clinical supervision. It is in line with the findings of the study done by Bampton (2011) on guidelines for clinical supervision of student nurses and midwives in Namibia, which found that a lack of knowledge and skills are some of the possible factors affecting clinical nursing learning and the performance of student nurses. Other factors identified by Mills Francis and Bonner (n.d.) on mentoring, clinical supervision and preceptoring: clarifying the conceptual definition for Australian rural nurses were increasing demand for advanced practise but limited opportunities to up to skills and maintain practical skills. Magobe ET. al.'s (2010) study findings revealed that a lack of continuing education by the registered nurses/preceptors for student supervision was one of the reasons why they did not have adequate knowledge and skills to guide students in PHC clinical fields. A study by Pillay and Matshali (2008) revealed that some institutions lacked trained staff to carry out supervision, and they end up using supervisors without experience. A study by Frankel (2008) indicated that practitioners, including registered nurses, needed to consider aspects of their practice that could be changed, and they need guidance to take them through the process of implementing changes. Regarding the need of training registered nurses, they have the following concerns:

"Some of the things included in your course requirement are new to us; therefore, we need to be updated if we have to continue supervising students."

"Most of us are not up-to-date with the latest development because no workshop on supervision has been held for us".

"Practice programmes for student nurses are not always clear for us in the wards. What is not clear to supervisors is what students on different levels should know and learn at practical settings."

"I did not receive any communication on what is expected from me regarding the supervision of students; therefore, I am not sure whether what I provide is correct."

The result of a study done by Magobe et al., (2010) indicated that some clinical supervisors lack the necessary knowledge due to the 
fact that they do not have the required qualifications, and thus they could not improve student clinical competence. Findings of a study by Pillay and Matshali (2008) revealed that some institutions lack trained staff to carry out supervision, so they use clinical supervisors without any nursing education qualification. This is supported by the results of a study by DavahanaMaselelele (2000) on problems with the integration of theory and practice in a selected clinical setting, of which they found that tutors were not fully involved in the accompaniment of students due to a lack of knowledge and confidence with regards to clinical skills.

Conclusions of a study done by Papastvrou, Lambrinou, Tsangari, Saarikoski and Leino-Klipi (2009), recommended that the role of the mentors needs to be reformed, strengthened and supported The latter is supported by McCarty and Higgins (2003) who indicated that appropriate clinical knowledge and skills help to prepare and support the preceptor for the role of mentoring.According to Steven (2007); Whitaker (1999) and UNAIDS (2005), training and development are essential for achieving individual changes through learning. However, scholars further argue that the focus of learning cannot be confined to knowledge and skills, as individual beliefs, values and attitudes play an important role in facilitating learning and in the successful implementation of planned organizational change (Forrest, Strange, Oakley \& RIPPLE Team, 2002; Bradley, 2006). Another study shows that registered nurses exhibit poor clinical competences, which can lead to erroneous health care assessment, patient management as well as student supervision (Kyrkjebo\&Hage, 2005). In a study conducted by Sardo et al., (n.d., the conclusion reached supports the need for training supervisors so as to enable them to carry out supervision. Lock woodRayermann's (2003) study revealed that some registered nurses who are supervising students are just selected based on the mere availability of human resources, leading to the fact that those selected feel inadequate and ill-prepared for their supervision role therefore they need some education and training on supervision.

- Supervisors are providing in-effective clinical supervision to student nurses

The results of this study revealed that there is a shortage of materials needed during student guidance and supervision in clinical practices.

The following quotations are evidence of the above findings from registered nurses:

"For me, supervision is too challenging because the shortage of equipment is a problem; it interferes with or enables one to carry out his task. One may be willing to teach students but there is a shortage of the necessary equipment, for example, gowns and caps, or even no dressing packs because without necessary, the equipment, the procedures and carrying out of nursing care will be done in a wrong way, and this will not contribute to student learning."

"Most of the time we order the materials needed to provide nursing care, for example syringes and dressing packs but we don't get them because they are out of stock. This demoralizes us when it comes to teaching students; we are not able to teach them if we don't have the necessary materials."

"It is difficult to learn some procedures because of a lack of materials like cottons swabs, and dressing materials and instruments; students are not able to learn how procedures are done if there are no necessary equipment."

In another study done by Magobe et al., (2010), participants indicated that there was really a shortage of equipment like Baumano meters and drugs which were preventing them from working effectively and to guide student nurses properly, in order for them to become competent on what they are doing. Moeti et. al. (2004) Concur with the above findings, by stating that due to the shortage of staff and high bed occupancies, it was difficult for experienced professional nurses to guide and supervise newly-registered nurses sufficiently. The situation becomes frustrating when the equipment which was supposed to be used in patient care is not available. This concurs with Ehlers, Bezuidenhout, Monareng and Jooste (2003) who have stated that the reason why South African registered nurses leave the country and go to work in other coun- tries was due to a lack of resources within the South African health system.

Based on the findings above, students and registered nurses' experiences regarding staff and equipment, it was revealed that the shortage of equipment hampers the clinical supervision process of student nurses in a negative manner. The same results were revealed by a study done by Jackson et al., (2001), that the shortage of staff and materials influenced the quality health care and supervision negatively.

Clarke et al. (2003) conducted a study which indicated that a shortage of materials restricted the opportunities for the supervisors to provide proper clinical supervision.

These views concur with Carlson et al (2003) whose study findings revealed that the shortage or absence of equipment leads to staff helplessness and frustration.

The researcher fully concurs with the above findings in that, as a lecturer at the University of Namibia's Nursing Department, she is also confronted with a similar situation in which registered nurses advised her during consultations at clinical fields that they did not have time to teach and supervise students mainly because of the material shortages.

\subsection{Theme 3: Non-conducive environment for clinical supervision}

The study revealed that the clinical environment where the supervision of student nurses is taking place was not conducive. This was a concern for most of the participants, both students and registered nurses. They felt that it was impossible for registered nurses to provide effective clinical supervision due to the shortage of materials. Participants also indicated that they experienced poor interpersonal relationships and poor communication during the process of clinical supervision; these were both between student nurses and supervisors and among supervisors. This needs urgent attention because it hampers clinical supervision in a negative manner. For this, the following sub themes were identified during data analysis:

- Poor interpersonal relationships between supervisors and students hinder the clinical supervision of student nurses:

It was mentioned by the student participants that the interpersonal relationships between nurses in the wards and student nurses is not always what it should be. This has a destructive implication when it comes to learning. Poor interpersonal relationships lead to poor communication.

The following statements from student nurses participants support this:

"I really have been discouraged by the way supervisors approach students during their practical feedback. The way of correcting students makes me to feel bad because most of the supervisors are only concentrating on the mistakes done by the student as if the student did not do anything correct during the procedure. I don't know what to do; this really makes me lose my interest in practice and I am always afraid of approaching them to attend to me."

"The supervision given, I can say is better. I am saying so because some registered nurses are not willing or interested to work with students. They just want to keep students in the unit but if they are doing something they don't want to work with students or they don't answer students' questions, they only say they are too busy and sometimes when doctors are doing procedures they don't inform students to attend."

"I experience a lot of problems with the supervisors in the ward because not all registered nurses are friendly."

"Registered nurses are not interested in supervising student nurses to learn; they are only interested in manpower to do transport duties."

Registered nurses also complained about the attitude of students towards them in wards:

"One of the challenges is the students' attitude, and they are not interested in practicing nursing or even in their learning, and it causes difficulties in supervising. With attitude, I mean a disposition or a tendency to respond negatively or positively towards a 
certain thing because you may find that students are absent from duty, and sometimes they are not interested in what you are doing and at the end of the session they will end up not learning anything. I say they are not interested meaning the negative attitude revealed by absenteeism of student nurses at clinical settings and during the practical demonstration."

While conducting the study, the researcher noted the need for positive attitude changes of registered nurses and students towards clinical supervision. In the study done by Van Rhyn and Gontsana (2004), participants reported about an inadequate interaction and communication among supervisors and between supervisors and student nurses, which includes unfriendly registered nurses obstructing students from asking questions. The findings of a study done by Kapucu and Bulut (2011) on the interaction with clinical nurse participants stated that they are expecting respect and positive feedback from clinical nurses because generally positive feedback increased the levels of interaction and they were given positive support in this regard, although it was found that clinical nurses were just asking them questions and criticizing them.

Other findings from a study done by Ohaja (2010), on the support for learning in the clinical area experienced by post registration student midwives, found that the clinical staff's attitude was not conducive to provide the level of support required by students (Ohaja, 2010). It was characterised by lack of both recognition and positive feedback.

Most of the participants of this study were of the opinion that positive behaviour and attitudes regarding clinical supervision issues will promote open registered nurses/student nurse communication. Participants believed that they needed to change their behaviour and attitude towards clinical supervision issues and they should offer effective supervision in order to contribute to the improvement of student learning.

Maxwell (2006) highlighted that an individual's commitment to behavioural change is reinforced by being involved in planning, by engaging in self-monitoring, and by conducting frequent "selfawareness checks". Maxwell (2006) also argued that positive reinforcement can help change behaviour. However, change will not be lasting if an individual does not have an environment that supports activities and the internal motivation to make it a lifelong lifestyle. When these elements are present, reinforcement programmes are useful. Thus motivation is very important to counteract possible resistance. Resistance always hinders change because of the complex nature of change (Taylor, 2004).

Taylor (2004) suggests that when change is planned, an implementation time frame should be drawn up, as any delay in implementation makes it difficult for people to let go of the old and accept the new.

- Poor guidance of student nurses by registered nurses Poor guidance of student nurses by registered nurses

The student nurses who participated in this study revealed several experiences regarding poor guidance by registered nurses, leaving them unsure, causing them with frustrations, with feelings of being abandoned and not regarded as part of the team. The findings of a phenomenological study conducted by Shin (2000) with Korean student nurses about their clinical supervision indicate that the feelings of abandonment were high amongst the Korean student nurses because the head nurses or preceptors also had other duties to attend to, other than being with student nurses, thus leaving them alone. Student nurses reported that when they went to the clinical settings and no longer had continuous supervision, they felt abandoned. Student nurse participants for this study raised their concerns by stating the following:

"Some supervisors don't want students to practice difficult procedures like drawing of blood samples; they only want students to do full wash every day (angrily); how will students learn other procedures?"

"We are not properly supervised during clinical practice; they only leave us alone to do the work on our own."

"Some supervisors do not care about students' differences; they end up doing some times demonstrations and explaining things in their local language, not caring about those who do not understand them".

"Registered nurses are not interested in teaching students; some tell students that they are tired, some answer by saying that they are not for student teaching but for work."

A study done by Van Rhyn and Gontsana (2004) reported that participants were feeling discouraged and they had no interest because of the negative attitude of staff members at clinical practice settings. According to Pillay and Matshali (2008), some participants in their study view their negative experiences regarding guidance by reporting that they were not receiving academic support; they were seen as a burden by unit staff. In addition to that, they also stated that they were left to function independently, even when they required some guidance.

Similar findings again were obtained by Carlson et al (2003), where it was reported that student nurses were left un-attended, with nobody checking whether what they are doing is right or wrong. The same study reported a lack of guidance and support of student nurses by nursing personnel in clinical practice.

The findings of the study done by Magobe, et al (2010) indicate that participants voiced their experiences by indicating a lack of the provision of feedback. The above-mentioned findings are supported by a study done by Sharif and Masoumi (2005, p. 6), which found that ward staff were not concerned about what students learned; they were busy with their duties and they were unable to have both educational and service roles.

A study done by Frankel (2008) revealed that supervision was not done across the organization due to a lack of confidence, inexperience and a lack of supervision training on the part of the supervisors. Not only students need support but also those providing supervision need the same support to enable them to provide effective clinical supervision. The same experiences were reported in the study done by Waldock (2010), where it was indicated that nurses lack support from the nursing school and resultantly health care providers cannot efficiently execute their supervision role. According to the results of a study by Ohaya (2010), participants expressed the need for staff to take responsibility for the provision of learning support to student nurses while doing their clinical practice.

- Poor interpersonal relationship between supervisors and students

It was mentioned by the student participants that the interpersonal relationships between nurses in the wards and student nurses is not always what it should be. This has a destructive implication when it comes to learning. Poor interpersonal relationships lead to poor communication.

The following statements from student participants support this:

"I really have been discouraged by the way supervisors approach students during their practical feedback. The way of correcting students makes me to feel bad because most of the supervisors are only concentrating on the mistakes done by the student as if the student did not do anything correct during the procedure. I don't know what to do; this really makes me lose my interest in practice and I am always afraid of approaching them to attend to me."

"The supervision given, I can say is better. I am saying so because some registered nurses are not willing or interested to work with students. They just want to keep students in the unit but if they are doing something they don't want to work with students or they don't answer students' questions, they only say they are too busy and sometimes when doctors are doing procedures they don't inform students to attend."

"I experience a lot of problems with the supervisors in the ward because not all registered nurses are friendly."

"Registered nurses are not interested in supervising students to learn; they are only interested in manpower to do transport duties."

Registered nurses also complained about the attitude of students towards them in wards:

"The supervision of student nurses at clinical settings is very poor despite students being sent there to be taught; students are being underestimated, manipulated, called funny names and sent around 
to do other work like to go get results from the laboratory rather than to be taught on how to do procedures and they have a tendency of liking pupil nurses only."

"One of the challenges is the students' attitude and they are not interested in practicing nursing or even in their learning and it causes difficulties in supervising. With attitude I mean a disposition or a tendency to respond negatively or positively towards a certain thing because you may find that students are absent from duty and sometimes they are not interested in what you are doing and at the end of the session they will end up not learning anything. I say they are not interested meaning the negative attitude revealed by absenteeism of student nurses at clinical settings and during the practical demonstration."

Musarurgwa (2008) defines attitude as a complex system comprising the person's beliefs about the object and his/her feelings towards the object. Attitudes are learned, and they can be changed if deemed necessary. An attitude can also be defined as an intense feeling of a positive or negative effect for or against an object/subject. While conducting the study, the researcher noted the need for positive attitude changes of registered nurses and students towards clinical supervision. In the study done by Van Rhyn and Gontsana (2004), participants reported about an inadequate interaction and communication between supervisors and between supervisors and students, which includes unfriendly nurses obstructing students from asking questions. The findings from a study done by Kapucu and Bulut (2011) on the interaction with clinical nurse participants stated that they are expecting respect and positive feedback from clinical nurses because generally positive feedback increased the levels of interaction and they were given positive support in this regard, although it was found that clinical nurses were just asking them questions and criticizing them. Other findings from a study done by Ohaja (2010), on the support for learning in the clinical area experienced by post registration student midwives, found that the clinical staff's attitude was not conducive to provide the level of support required by students (Ohaja, 2010). It was characterised by lack of both recognition and positive feedback.

Most of the participants of this study were of the opinion that positive behaviour and attitudes regarding clinical supervision issues will promote open registered nurses/student nurse communication. Participants believed that they needed to change their behaviour and attitude towards clinical supervision issues and they should offer effective supervision in order to contribute to the improvement of student learning.

Maxwell (2006) highlighted that an individual's commitment to behavioural change is reinforced by being involved in planning, by engaging in self-monitoring, and by conducting frequent "selfawareness checks." Maxwell (2006) also argued that positive reinforcement can help change behaviour. However, change will not be lasting if an individual does not have an environment that supports activities and the internal motivation to make it a lifelong lifestyle. When these elements are present, reinforcement programmes are useful. Thus motivation is very important to counteract possible resistance. Resistance always hinders change because of the complex nature of change (Taylor, 2004). Further the author suggests that when change is planned, an implementation time frame should be drawn up, as any delay in implementation makes it difficult for people to let go of the old and accept the new.

- Poor communication among supervisors and students

Some participants indicated that poor communication is sometimes a stumbling block in student supervision. It seems that this resulted in a situation where lecturers and registered nurses did not communicate well among themselves and with students about what they should learn and practice.

This was evident in the following accounts:

Registered nurses expressed their lived experiences as follows:

"There is poor communication between supervisors. With poor communication between supervisors I mean not reporting to each other problems encountered during student supervision like misconduct and student progress as well as other problems encoun- tered by students during practical placement that need to be dealt with to enhance or help promote student learning."

"Through communication supervisors will learn and be aware of what students know and what they don't know and also what they need and will be able to help them with."

Student nurses expressed the following:

"There is no contact between the registered nurses and the lectures."

"Lecturers and registered nurses in the wards are not helping each other in supervision because they don't sit and discuss together on what is expected from each of them regarding student supervision."

"Supervisors are not sharing what they experience during supervision. I believe that if they want to help us better they should give each other feedback on how the task is performed."

Effective communication is the key to forming relationships between nurses. However, not all nurses use appropriate forms of communication during clinical teaching (Wilkes, 2006, p. 41-42). Negative experiences can occur when nurses grudgingly accept students, making them feel rejected and devalued. Nurses may be unaware that their communication negatively affects student learning and performance. Interpersonal relationships can be defined as any of the many and varied relationships which exist within each individual, and between individuals and groups of people and the greater community, and globally. These relationships include, but are not limited to, the individual's relationship with him/herself, friendships, and romantic, collegial, and community relationships (Rew, 2005). On the other hand, the learning environment has to meet the standards laid down by the country's nursing regulatory body such as student learning experiences and evaluations, environment, quality assurance mechanisms and appropriate and accessible learning opportunities.

\section{- Hospital stock shortage}

The results of this study revealed that there is a shortage of materials needed during student guidance and supervision in clinical practices. The following quotations are evidence of the above findings from registered nurses:

"For me, supervision is too challenging because the shortage of equipment is a problem; it interferes with or enables one to carry out his task. One may be willing to teach students but there is a shortage of the necessary equipment, for example, gowns and caps, or even no dressing packs because without necessary, the equipment, the procedures and carrying out of nursing care will be done in a wrong way, and this will not contribute to student learning."

"Most of the time we order the materials needed to provide nursing care, for example syringes and dressing packs but we don't get them because they are out of stock. This demoralizes us when it comes to teaching students; we are not able to teach them if we don't have the necessary materials."

"It is difficult to learn some procedures because of a lack of materials like cottons swabs, and dressing materials and instruments; students are not able to learn how procedures are done if there are no necessary equipment."

In a study done by Magobe et al., (2010), participants indicated that there was really a shortage of equipment like baumanometers and drugs, which were preventing them from working effectively and to guide student nurses properly, in order for them to become competent on what they are doing. Moeti ET. al. (2004) Concur with the above findings, by stating that due to the shortage of staff and high bed occupancies, it was difficult for experienced professional nurses to guide and supervise newly-registered nurses sufficiently. The situation becomes frustrating when the equipment which was supposed to be used for patient care is not available. This concurs with Ehlers, Oosthuizen, Bezuidenhout, Monareng and Jooste (2003) who have stated that the reason why South African registered nurses leave the country and go to work in other countries was due to a lack of resources within the South African health system. Based on the findings above, students and registered nurses' experiences regarding staff and equipment, it was revealed that the shortage of equipment hampers the clinical su- 
pervision process of student nurses in a negative manner. The same results were revealed by a study done by Jackson et al., (2002), that the shortage of staff and materials influenced the quality health care and supervision negatively.

Clarke et al. (2003) conducted a study which indicated that a shortage of materials restricted the opportunities for the supervisors to provide proper clinical supervision.

These views concur with Carton et al (2003) whose study findings revealed that the shortage or absence of equipment leads to staff helplessness and frustration.

The researcher fully concurs with the above findings in that, as a lecturer at the University of Namibia's Nursing Department, she is also confronted with a similar situation in which registered nurses advised her during consultations at clinical fields that they did not have time to teach and supervise students mainly because of the material shortages.

\section{Conclusion}

It was clear from the findings that registered nurses did not provide effective clinical supervision to nursing students due to challenges they were encountered with during the execution of the clinical supervision. The challenges experienced are indicated in table 1 . The findings will be used as basis in for the educational programme that will be illustrated in part 2

\section{Acknowledgment}

Acknowledgement is accorded to the following people and institutions: The University of Namibia (UNAM), The Ministry of Health and Social Services and hospital management for the Oshakati Intermediate Hospital for allowing me to conduct this study at their health facility and for the kind support offered during this study. All registered nurses and nursing students who had taken part in this study, for their contributions and co-operations that made this study possible.

\section{References}

[1] A dictionary of nursing.(2008). Clinical supervision. Retrieved from: http:www: encyclopaedia. com.doc/1062/clinical supervision html.

[2] Abid-Haybaghery, M., 6 :93-101Evident Based practice : Iranian nurse perception Wold view Evid, Based Nurse 2009, 6 : 93-101 [PubMed] http://dx.doi.org/10.1111/j.1741-6787.2009.00149.x.

[3] Addis, G. \& Karadag, A. (2003).An evaluation of nurses' clinica teaching role in Turkey.Nurses Education Today, 23, 27-33. http://dx.doi.org/10.1016/S0260-6917(02)00159-4.

[4] American Association of College of Nursing, (2011). American Association of College of Nursing faculty shortage fact sheet Retrieved 2.6.2014, from http//www.aacnnche/mediarealtioNrsgShortageFS pdf.

[5] Andrews, G.J., Brodie, D.A., Andrews, J.P., Hilian,E., Thomas, B.G., Wang, J. \&Rixon, L., (2006) Professional roles and communications in clinical placement A qualitative study of nursing students perceptions and some models for practice International Journal of Nursing Studies http://dx.doi.org/10.1016/j.ijnurstu.2005.11.008.

[6] Babbie, E. \& Mouton, J. (2007).The practice of social research $\left(9^{\text {th }}\right.$ ed.). Belmont. Wadsworth.

[7] Bampton EL 2011 Guideline for clinical Nursing of the pupil nurse and Midwife in Namibia unpublished thesis submitted in fulfilment of the requirement for the dedree of master degree of Nursing Science University of Namibia, Windhoek.

[8] Begat, I. \& Serevinsson, E. (2005).Nurses' satisfaction with their work environment and the outcome of clinical nursing supervision on nurses 'experience of well-being.Journal of Nursing Management, 13, 221-223. http://dx.doi.org/10.1111/j.1365-2834.2004.00527.x.

[9] Bernard, H.R., Ryan, W. G., (2010) Analysing qualitative data: Systematic approaches. Los Angeles, CA: Sage.

[10]Bezuidenhout, M.C. (2003). Guideline for enhancing clinical supervision.Health SA Gesondheid, http://dx.doi.org/10.4102/hsag.v8i4.142.

[11]Boeije, H. (2009). Analysis in qualitative research. California: SAGE.
[12]Bradley, L. (2006). Combating a Negative Attitude.EzineArticles (October, 02), Retrieved May, 2, 2008 at http://ezinearticles.com/?Combating-a-Negative-Attitude\&id=78538. H.R., Ryran, G.W. (2010) Qualitative Data. Systematic Approaches. Sage Publication Inc.

[13]Brink, H. (2007).Fundamentals of research methodology For Health Care Professionals. Jute and Company (Ltd).

[14]Brown, L., Herd, K., Humphries, G. \& Parton, M. (2004). The role of the lecturer in practice placement: What do students think? Nurse Ed$\begin{array}{lll}\text { ucation Today } & \text { 5(2), } & \text { 84-90. }\end{array}$ http://dx.doi.org/10.1016/j.nepr.2004.03.006.

[15] Brunero, S., Stein-Parbury, J., (2011). The effectiveness of clinical supervision in nursing : an evidence based Literature review Australian Journal of Advance Nursing 2011; 25:86-94

[16]Burns I Paterson IM 2004 Clinical practice and placement SUPPORT; Supporting LEARNING IN PRACTICE Nurse Education in practice Accessed May 132005 at www.elsevirheath.com/journal/nepr

[17]Carlson, S., Kotze, W.J. \& Van Rooyen, D. (2003). Accompaniment needs of first year nursing students in the clinical learning environment. Curationis26 (2): 30-39.

[18]Castledine, G., 2002 Students must be treated belter in clinical area British Journal of Nursing 11:18 1222

[19]Clarke C.L., Gibb C.E., Ramprogus, V. ,Clinical earning environment an evaluation of an innovative role support preregistration nursing placements" Learning in Health and Social care2003 vol.2 no2 pp 105 115 http://dx.doi.org/10.1046/j.1473-6861.2003.00044.x.

[20]Clayton \& Gorman, G.E. (2005). Qualitative research for the information professional.A practical handbook.Facet Publishing.

[21]Consedine, M. (2004).Clinical values and possibilities.Available on line at http:www.tidal model co uk/clinical-supervision.Htm. Retrieved on 9.1.2006.

[22]Creswell.J.W. (2008). Educational Research: Planning, Conducting and Evaluating Qualitative \& Quantitative research. Pearson Education: New Jersey.

[23]Dale, B., Leland, A. \& Dale, J.D. (2013). What factors facilitate good learning experiences in clinical studies in nursing Bachelor Student's Perceptions. Retrieved http:/www.hindawi.com/journal/isrn/2013/626879.

[24]Davhana-Maselesele, M. (2000).Problems in integration theory with practice in selected clinical nursing situations. Unpublished master's dissertation Pretoria University of South Africa.

[25]Part of an integral model assessment. Educational Assessment12 (2), 112-135.

[26]De Vos, A.S. (2007). Research at the grass roots. Pretoria: Van Schaik publishers.

[27]De Vos, A.S., Strydom, H., Fouche, C.B. \& Delport, C.S.L. (2007).Research at grassroots for Social sciences and human service professions. Pretoria: Van Schaik.

[28]Ehlers, V.J., Bezuidenhout M.C., Monareng, L.V. \& Jooste, K. (2003). Post basic nursing student perception of the emigration of nurses. SA Gesondheid8 (4), 24-37.

[29]Frankel, A. (2000). Nurse learning style promoting better integration of theory into practice.Nursing Times 105, 24-27.

[30]Forrest, S., Strange, V., Oakley, A. \&The RIPPLE team. (2002) A comparison of student evaluations of a peer-delivered sexuality education programme. Greensides.

[31]Forrester C 2008 Terminal care: Psychosocial needs of significant others (ss131-169) the social Work Practitioner Reserch Retrieved May 3. 2013 at http/www.uj.ac.za

[32] Gorman, G.E. \& Clayton, J. (2005).Qualitative research for the information professional: A practical handbook: Facet Publishing.

[33]Hlongwa, E. (2003). .Diplomate's perceptions of their psychiatric nursing component of the four-year comprehensive programme.Retrieved July 17, 2008 from http://www.etd.unisa.ac.za/.

[34]Holliday, A. (2003). Doing and Writing: Qualitative Research. SAGE Publications: London, Thousand Oaks.

[35]Ip, W.P. \& Chan, D.C.K. (2005). Hong Kong Nursing Students' perception of the clinical environment: a questionnaire survey. International Journal of Nursing studies42, 665-672. http://dx.doi.org/10.1016/j.ijnurstu.2004.09.019.

[36]Jackson, D; Mannix, J.2001 Clinical nurse as a teacher: Insight from students of nursing in their first semester of study. Journal of clinical Nursing 10:2.270-277.

[37] Kaphagwani, N.C. \&Usch, U. (2013).Analysis of nursing students learning experiences in clinical practice: Literature Review. Retrieved May 22014 at http://www.krepulisher.com/.../sSEm-.07-3-181-13393-usch-ute.pdf.

[38]Kapucu, S. \& Bulut, H. (2011). Turkish nursing students' view of their clinical learning environment: a focus group study. Pak J Med Sci 2011:27(5), 1149-1153./. 
[39]Kelly, C. (2007). Theory of Experiential Learning.The internet Test Journal, 3(9).

[40]Kemper, N. (2007). Win-win strategies help relieve preceptor burden: Nursing Management, 38(2) 3-12. http://dx.doi.org/10.1097/00006247-200702000-00004.

[41]Kirby, D. (2007). Emerging Answers Summary: Research findings on programs to reduce teen pregnancy and sexuality transmitted diseases. Washington, DC: National Campaign to Prevent Teen and unplanned pregnancy. $2007 \mathrm{http}$ ///www.thenationalcampaign.org/ea2007/...

[42]Klerk, K. (2010). Clinical supervision in selected hospitals; Cape Town. Reflection on registered nurses live experiences Magister Curationis University of Western cape South Africa. Retrieved 28.7.2014 at http://etduwc-ac.29/bitstream/handle/11394/.176/klerk-mcur-2010 pdf? Sequence.

[43]Kobus, M. (2007).First steps in research. Van Schaik Publishers: Pretoria. SA.

[44]Krykjebo, J.M. \&Hage, I. (2005). What we know and what they do: Nursing students experiences of improvement knowledge in clinical practice. Nurse Education Today 25(3), 167-175. http://dx.doi.org/10.1016/j.nedt.2004.11.008.

[45] Lambert, V. \&Glecken, M. (2005). Clinical education facilitators A Literature review issues in clinical nursing. Education in Clinical practice, 14, 644-673.

[46]Landmark, B.T.H., Hansen, G.S., Bjones, I. \&Bohler, A.(2003). Clinical supervision factors defined by nurses as influential upon development of competence and skills in supervision.Journal of Clinical Nursing, $12, \quad 834-841 . \quad$ http://dx.doi.org/10.1046/j.13652702.2003.00813.x.

[47]Lockwood-Rayermann, S. (2003).Preceptor Leadership style and the nursing practicum.Journal of Professional Nursing, 19(1), 32-37. http://dx.doi.org/10.1053/jpnu.2003.7.

[48]Löfmark A., Thorkildsen, K., Räholm, M. \& Natvig, G.K (2012) Nursing student satisfaction from preceptors and teachers during practice. Nurse Education in Practice 2012;12:164 169;PMid.22225731http://dox.doi.org 10.1016/jnepr.2011.11.005.

[49]Longley, M., Shaw, S. \& Dolan, G. (2007).Towards 2015 alternative Scenarios for nursing Health Education in UK in 2015 retrieved 25.4.2012

from http//wwwnmckorg/document/Research520paper/Nursing520Towards 52020155summarypdf.

[50]Mabuda B.T., Portgieter, E. \& Albert, U.U. 2008 Student nurse experiences during clinical practice in the Limpopo Province Curationis 31 (1):19-27.

[51]Magobe, N.B.D., Beukes, S. \& Muller, A. (2010). Reason for student poor clinical competence in Primary health care; clinical nursing diagnosis treatment and Care: Health SA Gesondheid15 (1) Art. \# 5256 pages Doi 104102/hasdv15i.525.

[52]Maxwell, L. (2006). Context and "Contextualization" in Sex relationship. ( $2^{\text {nd }}$ ed.). Lawrence Erlbaum Associates, Publishers: Mahwah, New York.

[53].McCarty, M. \& Higgins, A. (2003).Moving to an all graduate profession preparing preceptors for their role.Nurse Education Today, 9-95. http://dx.doi.org/10.1016/s0260-6917(02)00187-9.

[54] McLafferty, I. \& Morrison, F. (2004).Attitudes towards hospitalized older adults.Journal of Advanced Nursing40 (4), 446-453. http://dx.doi.org/10.1111/j.1365-2648.2004.03122.x.

[55] Mills, J.E., Francis, K.L. \& Bonner, A. (Undated).Mentoring Clinical supervision and preceptoring: Clarify conceptual definitions for Australian rural nurses. A review article.Retrieved on 31.7.2006 at http://rrh.diakin.au.

[56]Mochaki, N.W. (2001). Clinical teaching by registered nurses.Unpublished master's dissertation. Pretoria: University of South Africa.

[57]Moeti, M.R., Van Niekerk, S.E. \& Van Velden, C.E. (2004).Perception of the clinical competence of newly registered nurses in the North West Provence.Curationis,27(3), 72-84. http://dx.doi.org/10.4102/curationis.v27i3.1003.

[58] Musarurgwa, E.S. (2008). The evaluation of effectiveness of Sexuality education programme for adolescent. http:hdl.handle.net/10210/1582.

[59]Nurses facilitating supernumery nursing student nurses. Education Today, 23, 123-130.

[60]Ohaya M., 2010. Support for learning in clinical area The experience of Post registration student nurses Volume 2(1) 14:174-5

[61]Olivier, D.G., Serovich, J.M. \& Mason, T.L. (2005). Constraints and opportunities with interview transcription: towards reflection in qualitative research. Social Forces84 (2), 1273-1289. http://dx.doi.org/10.1353/sof.2006.0023.

[62] Papastvrou, E., Lumbrinou, E., Tsangari, H., Saarikoski, M. \&LeinoKlipi, H. (2009). Student nurses experiences of learning environment.
Nurse Education in Practice.Retrieved at journal homepage.www.elsevier.com/nep.

[63]Pillay, P. \& Matshali, N.G. (2008). Clinical supervision and support for the bridging programme student in the great Durban area South African Nursing Association. Curationis31 (4), 46-56.

[64]Polit, N.F., Beck, C.T., 2009) the nursing Research generating and Assessing Evidence for nursing practice. Lippincott Williams \& Wilkins Philadelphia.

[65]Preceptorship. (2003) Retrieved July 7. 2008 at http://www.nuigalway.ie/nursing/perseptorship.htm

[66]Qualitative Methodology available. Retrieved February 28.2009 at http:www.gov.mu/portal/sitencb/dcp/report qualitative mtd.doc.

[67]Rew, L. (2005). Adolescent health.A multidisciplinary approach to theory, research and intervention. University of Texas, Austin, SAGE Publications: Thousand Oak, London, New Delhi.

[68]Safadi, R.R., Saleh, M., Nasser, O.S., Amre H.M. \&Froclicher, E.S. (2011). Nursing students' perception of nursing - a descriptive study of four cohorts. International Nursing Review58, 420-427. http://dx.doi.org/10.1111/j.1466-7657.2011.00897.x.

[69]Saks, M. \& Allsop, J. (2007).Researching Health: Qualitative, Quantitative and Mixed Methods. SAGE Publications: Los Angeles.

[70]Sardo, D.S., Santos, M.R., Kock, M.C., Pires, R.M., Machado, P.P. \& Morais, E.E.A. (Undated).Condition and factors in nursing. Student Clinical Supervision.Retrieved on 2.6.2008 at www.foormatex.org/mite2005.

[71] Searle, C., Human, S. \&Mogtlane, S.M. (2009).Professional practice: a South Africa perspective. Johannesburg: Heinemann.

[72]Shank, G.D. (2006).Qualitative Research - A personal skills approach. Pearson Merrill, Prentice hall, Columbia: Ohio.

[73]Sharif, F. \& Masoumi, S. (2005). A Qualitative Study of Nursing Students' Experience of clinical Practice: The Cochrane Library.

[74]Shin, K.R. (2000). The meaning of clinical experiences of Korean nursing students.Journal of Nursing Education, 39(6), 259-265.

[75]Spouse, J. \& Redferm, L. (2000).Successful supervision in health care practice; promoting professional development. Malden: Blakwell Science.

[76] Steven, D. (2007). Boost the act of giving hope or support to someone, the expression of approval and support. Available from: Retrieved 01 November 2009 at http:/www.kidshealth.org/teen/your-body/take.

[77] Streubert, Speziale, H.J. \& Carpenter, D.R., (2007).Qualitative research in Nursing.Advancing the humanistic imperative. Philadelphia: J.B Lippincott.

[78]Tanner C.A., 2001 Competent based education the new panacea? Journal of Nursing education 40 (9) 387-8

[79]Taylor, L.S. (2004). Real parent. Retrieved accessed 28 November 2009 at: http://www.lewrockwell.com/taylor/taylor60.html.

[80] Van Ooijen, E. (2000). Clinical supervision in practical guide. Edinburg: Churchill Livingstone.

[81] Van Rhyn, W.J.C. \&Gontsana, M. (2004).Experiences by student nurses during clinical placement in psychiatric units in a hospital.Curationis. 2004 Nov 27(4):18-27. Retrieved at http:/www.ncbi.nlm.gov/pubmed/15712822. http://dx.doi.org/10.4102/curationis.v27i4.1014.

[82] Waldock, J. (2010). Facilitating student learning in clinical practice many nurses believe they are ill prepared an d poorly supported to supervise students Heavy workload also prevent effective teaching and learning taking place. Retrieved February 2, 2011 at

[83] Walliman, N. (2005). You're Research Project - a step-by-step guide for first-time researcher ( $2^{\text {nd }} \mathrm{Ed}$.). London: SAGE Publisher.

[84] Welman, E., Kruger, H. \& Mitchell, F. (2009).Research Methodology. Oxford University Press: South Africa.

[85] Whitaker DJ et al. (1999) Teenage partners' communication about sexuality risk and condom use: the importance of parent-teenager discussions. Fam PlannPerspect 1999; 31:117-21. http://dx.doi.org/10.2307/2991693.

[86]Wilkes, Z. (2006). The student- mentor relationship a review of litera$\begin{array}{llll}\text { ture Nursing } & \text { Standard, } & \text { 20(37), }\end{array}$ http://dx.doi.org/10.7748/ns2006.05.20.37.42.c4160.

[87] Williamson, T.L.A.F. (2005). Qualitative data analysis using data $\begin{array}{llll}\text { displays. Nurse } & \text { Researcher 13515578, }\end{array}$ http://dx.doi.org/10.7748/nr2005.01.12.3.7.c5944. 